\title{
MULTI-SPATIOTEMPORAL PATTERNS OF RESIDENTIAL BURGLARY CRIMES IN CHICAGO: 2006-2016
}

\author{
Jun Luo* \\ Department of Geography, Geology and Planning \\ Missouri State University \\ junluo@missouristate.edu
}

KEY WORDS: Spatiotemporal pattern, Spatiotemporal slice, Spatiotemporal weight, GIS, Getis-Ord $\mathrm{Gi}^{*}$, Burglary, Chicago

\begin{abstract}
:
This research attempts to explore the patterns of burglary crimes at multi-spatiotemporal scales in Chicago between 2006 and 2016. Two spatial scales are investigated that are census block and police beat area. At each spatial scale, three temporal scales are integrated to make spatiotemporal slices: hourly scale with two-hour time step from 12:00am to the end of the day; daily scale with one-day step from Sunday to Saturday within a week; monthly scale with one-month step from January to December. A total of six types of spatiotemporal slices will be created as the base for the analysis. Burglary crimes are spatiotemporally aggregated to spatiotemporal slices based on where and when they occurred. For each type of spatiotemporal slices with burglary occurrences integrated, spatiotemporal neighborhood will be defined and managed in a spatiotemporal matrix. Hot-spot analysis will identify spatiotemporal clusters of each type of spatiotemporal slices. Spatiotemporal trend analysis is conducted to indicate how the clusters shift in space and time. The analysis results will provide helpful information for better target policing and crime prevention policy such as police patrol scheduling regarding times and places covered.
\end{abstract}

\section{INTRODUCTION}

Mapping and analysis of crime patterns are crucial to policing policy making, policing resource allocation, crime prevention, and urban planning (Hill \& Paynich, 2014). As crime usually occurs at a certain place and at a certain time point, analysis of the crime patterns needs to address both space and time dynamics of crime occurrences. Spatiotemporal patterns of crimes have received intensive scholarly attentions in recent years (e.g.,Conrow, Aldstadt, \& Mendoza, 2015; Johnson, 2013; Ye, $\mathrm{Xu}$, Lee, Zhu, \& Wu, 2015; Zhang \& McCord, 2014). Investigating spatiotemporal dynamics of crimes requires the combination of a certain spatial scale and a certain temporal scale. A spatial scale used in the crime analysis usually conforms an administrative/census unit such as census tract and urban community (Ye \& Liu, 2012; Ye \& Wu, 2011). Temporal scale is more variable and is determined depending on research objectives. Combing the spatial and temporal scale in analysis enables us to explore the spatiotemporal dynamics of crimes.

One way to exploring spatiotemporal dynamics of crimes is to break up the data into multiple time snapshots and examine individual snapshots. This approach, however, does not utilize all the potential spatiotemporal relationships in the data, because the break-up time point is somewhat arbitrary. Applying a spatiotemporal neighbourhood to the entire dataset will overcome the drawbacks of time snapshot approach and capture all the potential spatiotemporal relationships in the dataset. The spatiotemporal neighbourhood is defined by both the spatial closeness and temporal closeness between features.

This paper investigates the spatiotemporal patterns of residential burglary crimes in Chicago from 2006 to 2016. Three spatial scales that are closely relevant to policing are examined: police district, community and police beat. The three spatial scales are integrated with three temporal scales: monthly scale with one- month interval from January to December, daily scale with onday interval from Sunday to Saturday within a week and hourly scale with two-hour interval from 12:00am to the end of the day. A spatiotemporal neighbourhood is defined for each combination of spatial and temporal scale. Using spatiotemporal neighbourhoods, the integrations of spatial and temporal scales will generate six types of spatiotemporal integrated dataset. Cluster analyses are then conducted to reveal the spatiotemporal patterns of residential burglary crimes in Chicago.

\section{STUDY AREA, DATA AND METHODOLOGY}

\subsection{Study area and data}

This research investigates the residential burglary crimes within City of Chicago from 2006 to 2016 (Figure 1). Burglary crime data are obtained from the data portal of City of Chicago (.https://data.cityofchicago.org/). Police district, community and police beat datasets were also obtained from the data portal. There were totally 3,304 residential burglary crimes in the City of Chicago between 2006 and 2016. Each crime record has street address, $\mathrm{x}, \mathrm{y}$ coordinates and time point attached. As aforementioned, the research investigates six types of combinations of spatiotemporal scales. Spatiotemporal aggregations are performed to generate dataset for each type of the spatiotemporal combination. For example, all crimes that occurred during January and within the same police beat will be aggregated/summarized into the police beat polygon. However, all crimes that occurred during February within the same police beat as above will be aggregated into another polygon but with the same spatial geometry as above. Therefore, there are redundant geometry polygons in the aggregated dataset. For each 


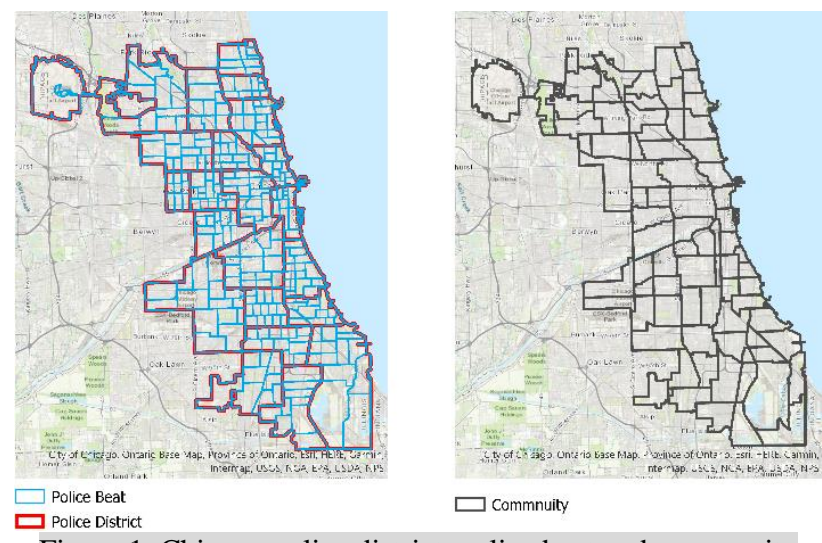

Figure 1. Chicago police district, police beat and community

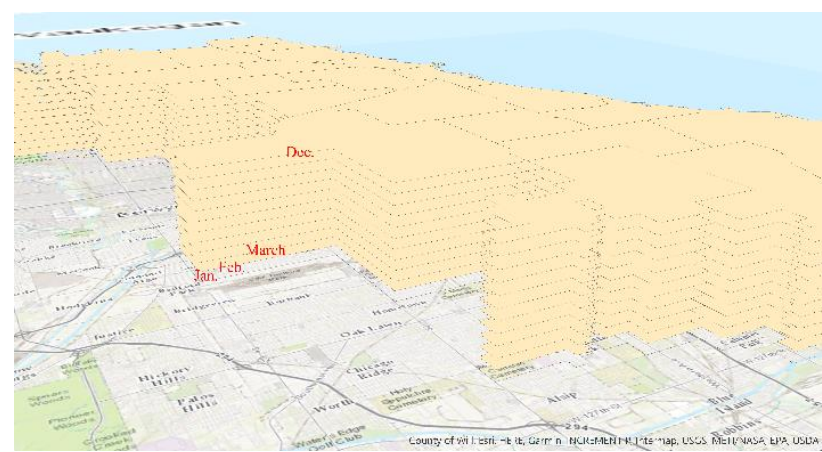

Figure 2. Spatiotemporal data slice of police districts at monthly temporal scale

spatial scale used in the study, there will be three types of timebased slices that contains the aggregated crime data (see Figure 2 for spatiotemporal slice examples). Each polygon in the aggregated dataset has time or time span properties generated from the aggregation process, such as 20:00-22:00, Monday and October. A Python tool was written to implement the multispatiotemporal aggregations of crime occurrences and generate the ASCII spatiotemporal weight matrix file for each type of spatiotemporal slice dataset.

\subsection{Spatiotemporal weight matrix}

In this study, the neighbouring relationship between polygon units at a certain scale (i.e, police district, community and police beat) is defined by the spatial contiguity and temporal closeness. Binary weight is used for the study. Specifically, for the monthly temporal scale, a polygon in the spatiotemporal slice dataset would have spatiotemporal weight 1 with those that are spatially contiguous with it and have time property that are within one month of the time property of the polygon. A zero-spatiotemporal weight is assigned to those that don't meet spatiotemporal closeness requirements; for the weekday temporal scale, a polygon in the spatiotemporal slice dataset would have spatiotemporal weight one with those that spatially contiguous with it and have time property within one day of the time property of the polygon. A zero-spatiotemporal weight is assigned to those that don't meet the spatiotemporal closeness requirements; for the two-hour temporal scale, a polygon in the spatiotemporal slice dataset would have spatiotemporal weight 1 with those that spatially contiguous with it and have time span property that are within two hours of the time span property of the polygon. A zero-spatiotemporal weight is assigned to those that don't meet the spatiotemporal closeness requirements. The Python tool as aforementioned generates the spatiotemporal weight matrix file for each spatiotemporal slice dataset.

\subsection{Spatiotemporal cluster analysis}

A Getis-Ord $\mathrm{Gi}^{*}$ statistic is applied to each of the six spatiotemporal slice data to reveal the spatiotemporal patterns of burglary crimes (Getis \& Ord, 1995; Getis \& Ord., 1992). The $G i *$ is a local spatial statistic that works by looking at each feature within the context of spatiotemporally neighbouring features. A polygon with a high value (i.e., the number of residential burglary crime occurrences) is considered a potential high value cluster if it is surrounded by other polygons with high values as well. The local sum for a polygon and its neighbours is compared proportionally to the sum of all polygons; when the local sum is very different from the expected local sum, and when that difference is too large to be the result of random chance, a statistically significant cluster is identified (Getis \& Ord, 1995). The standardized $G i^{*}$ statistic is given as follows:

$$
\begin{gathered}
G_{i}^{*}=\frac{\sum_{j=1}^{n} w_{i j} x_{j}-\bar{X} \sum_{j=1}^{n} w_{i j}}{S \sqrt{\frac{n \sum_{j=1}^{n} w_{i j}^{2}-\left(\sum_{j=1}^{n} w_{i j}\right)^{2}}{n-1}}} \\
S=\sqrt{\frac{\sum_{j=1}^{n} x_{j}^{2}}{n}-(\bar{X})^{2}} \\
\bar{X}=\frac{\sum_{j=1}^{n} x_{j}}{n}
\end{gathered}
$$

in which $x$ is the count of crimes in polygon $j$, wij is the spatiotemporal weight between polygon $i$ and $j, n$ is the total number of polygons in the spatiotemporal slice. The calculated value will be returned to each polygon. The larger the positive value is, the more intense the clustering of high values have; on the other hand, the smaller the negative value is, the more intense the clustering of low values have.

\section{RESULTS AND DISCUSSIONS}

\subsection{Overall trends}

The overall trends for the three temporal scales are shown in Figures 3, 4 and 5 respectively. Between 2006 and 2016, December has the most burglary crimes followed by October, August and January. There were least burglary crimes from February through April. In contrast, from May through November, more burglary crimes occurred but remained at the similar level. 


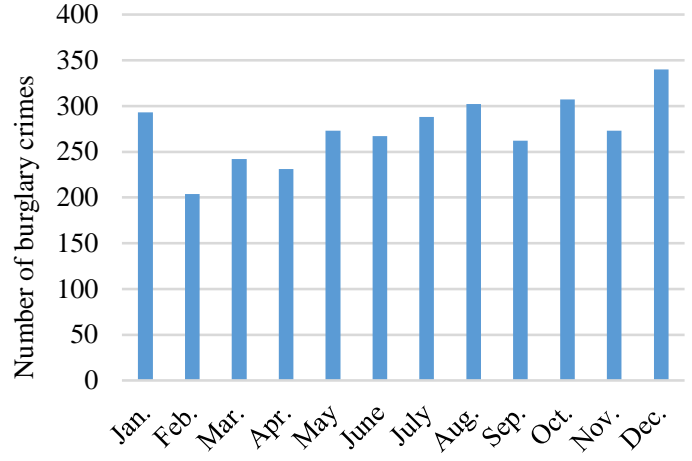

Figure 3. Overall burglary crimes by month

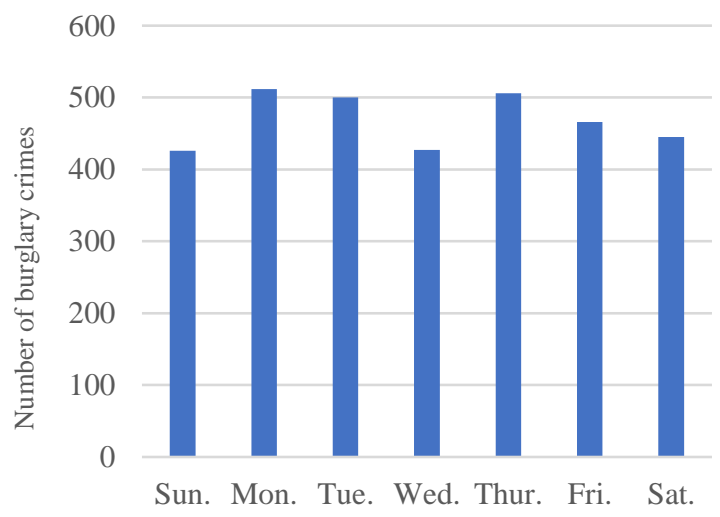

Figure 4. Overall burglary crimes by weekday

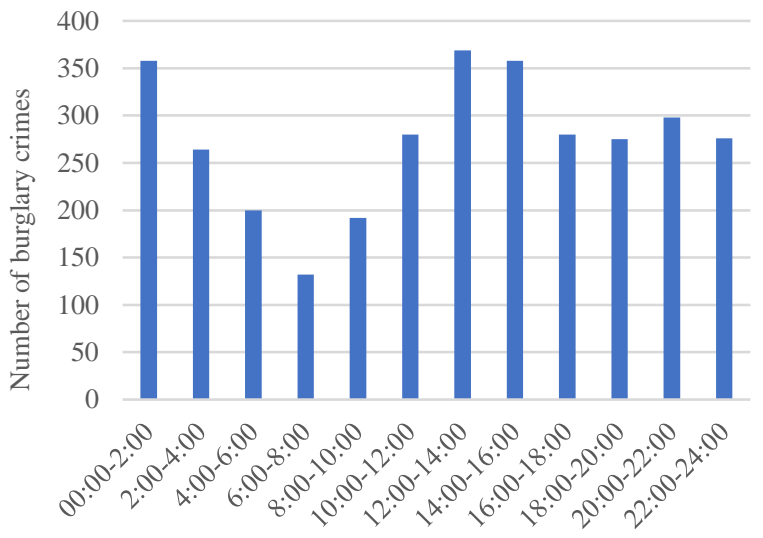

Figure 5 . Overall burglary crimes by 2 -hour interval in a day

\subsection{Spatiotemporal clusters of burglary crimes}

The $G_{i}$ * statistic is applied to each of the spatiotemporal slice and each polygon analysis unit in a spatiotemporal slice received a $z$ score and $p$-value that are used to infer the statistical significance. In this study, 99\% confidence level is used to determine if a polygon is a high value spatiotemporal cluster within a spatiotemporal slice. The six spatiotemporal slice data with $G_{i}{ }^{*}$ statistics provides us a rich set of information to explore the spatiotemporal patters of burglary crimes in Chicago between 2006 and 2016. Table 1 presents the top 3, ranked by number of significant clusters, time intervals of each temporal scale at each spatial scale that have significant spatiotemporal clusters.

At the police district level, high value clusters by month are shown in Figure 6. The clusters are concentrated in the middle to south parts of Chicago. Regarding the one month interval within a year, all the months have high value clusters except February, March and May. Note that one police district is identified as high

\begin{tabular}{|c|c|c|c|}
\hline & Police district & Community & Police beat \\
\hline \multirow{3}{*}{$\begin{array}{l}\text { Top } 3 \text { by } \\
\text { month }\end{array}$} & October & December & December \\
\hline & $\begin{array}{c}\text { November, } \\
\text { December and } \\
\text { September (tie) }\end{array}$ & November & November \\
\hline & August & $\begin{array}{c}\text { October and } \\
\text { September } \\
\text { (tie) }\end{array}$ & August \\
\hline \multirow{3}{*}{$\begin{array}{l}\text { Top } 3 \text { by } \\
\text { weekday }\end{array}$} & $\begin{array}{l}\text { Monday and } \\
\text { Thursday (tie) }\end{array}$ & Sunday & Tuesday \\
\hline & $\begin{array}{c}\text { Tuesday and } \\
\text { Wednesday (tie) }\end{array}$ & Friday & Wednesday \\
\hline & Friday & & Monday \\
\hline \multirow{3}{*}{$\begin{array}{l}\text { Top } 3 \text { by } \\
\text { 2-hour }\end{array}$} & $\begin{array}{l}12: 00-14: 00 \text { and } \\
14: 00-16: 00 \text { (tie) }\end{array}$ & $14: 00-16: 00$ & $\begin{array}{c}12: 00- \\
14: 00 \\
\end{array}$ \\
\hline & 10:00-12:00 & $12: 00-14: 00$ & $\begin{array}{l}14: 00- \\
16: 00\end{array}$ \\
\hline & $16: 00-18: 00$ & 0:00-2:00 & $\begin{array}{l}16: 00- \\
18: 00\end{array}$ \\
\hline
\end{tabular}

Table 1. Time intervals with most clusters

value cluster for nine months. At the weekday temporal level, as seen from Figure 7, high value clusters concentrate in the middle to south parts as well. All the weekdays have high value clusters. The same district with clusters for nine months has the highest weekday frequency. At the two-hour interval level (Figure 8), the concentration of high value cluster slightly expands to both south and north.

At the weekday temporal scale, Monday had the most burglary crimes followed by Tuesday and Thursday. Sunday and Wednesday had the least burglary crimes comparatively. Overall, within a day, burglary crimes concentrated from midnight to 2:00, 12:00 to 14:00 and 14:00 to16:00. 4:00 to 8:00, on the other hand, had the least burglary crimes between 2006 and 2016 . 


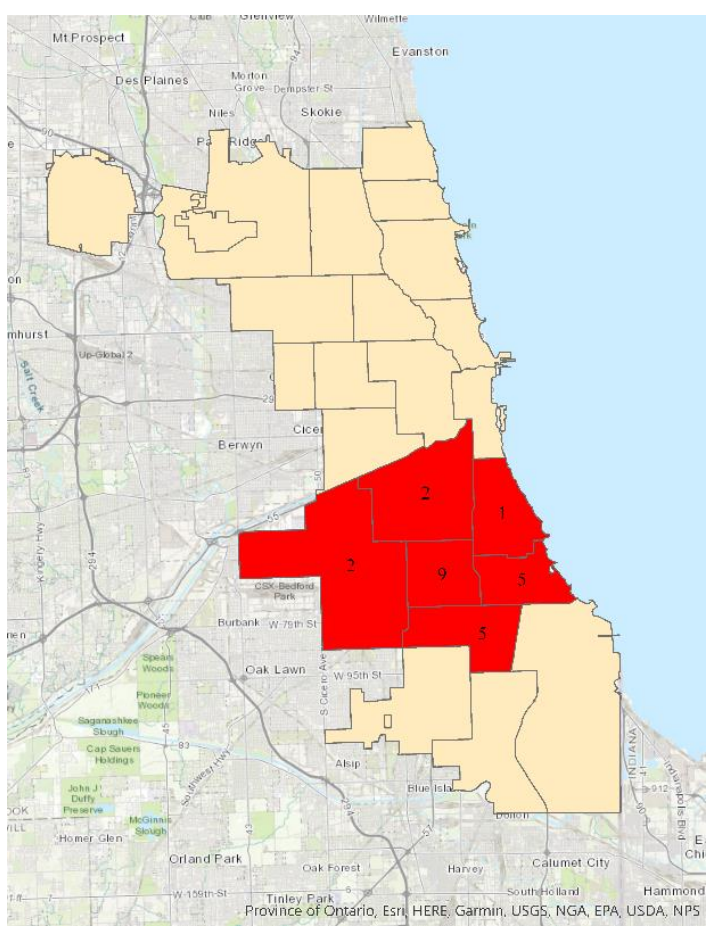

Figure 6. High value clusters by month at police district level (number in the polygon represents the frequency of clusters)

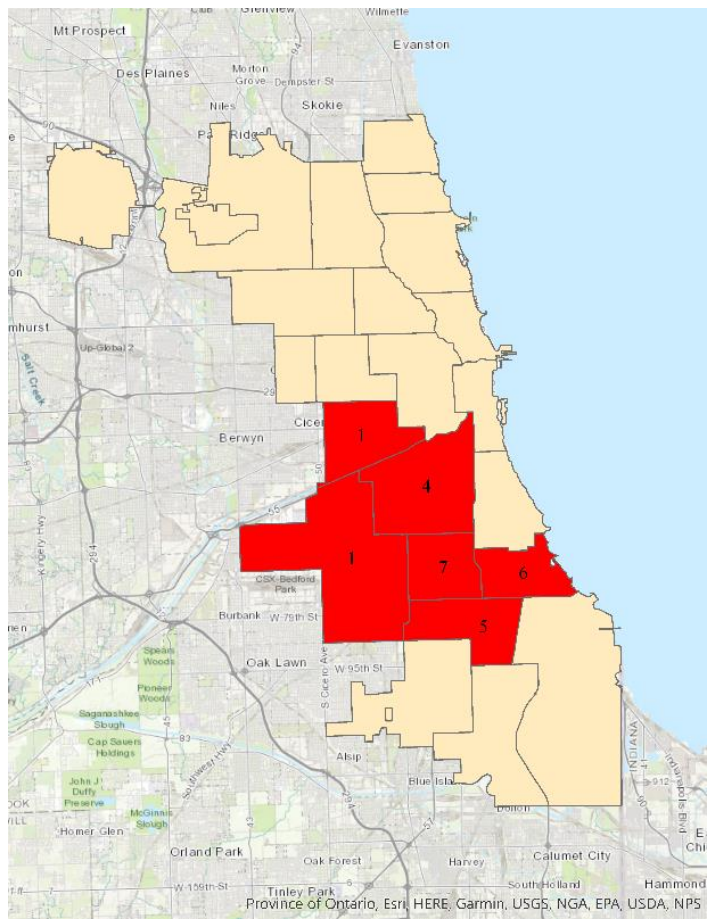

Figure 7. High value clusters by weekday at police district level

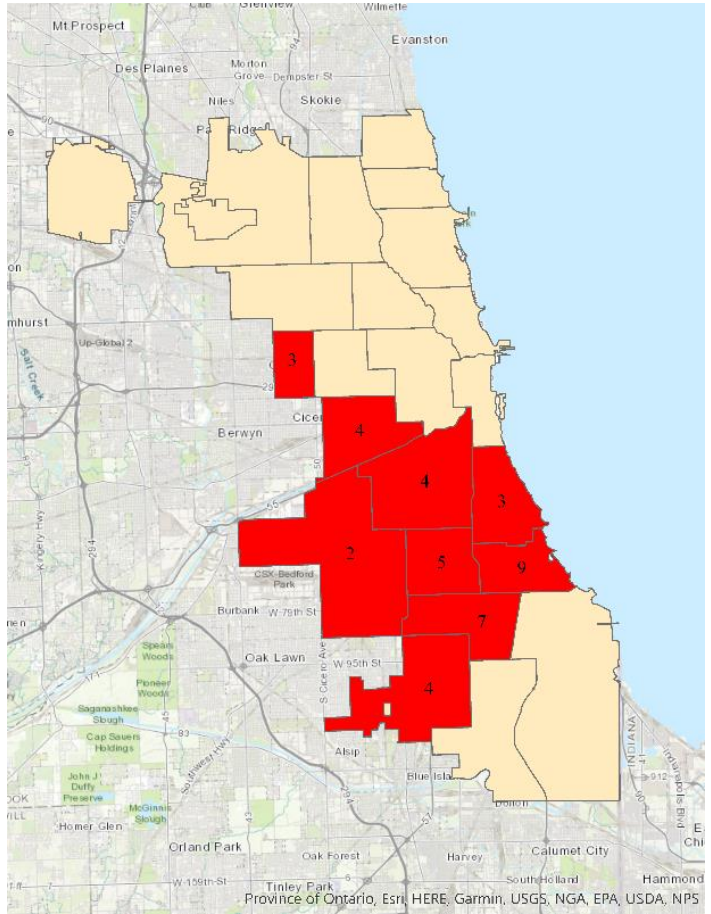

Figure 8 . High value clusters by 2 -hour interval in a day at police district level

Figure 9 shows the high value clusters by month at the community level. In contrast to the police district level, two separate concentration of high value clusters formed at this spatiotemporal scale. Two communities in the southern concentration have the most frequent clusters by month (10 clusters). At the weekday level, however, no concentration of clusters formed as only five communities are identified as high value clusters (Figure 10). As shown in Figure 11, two-hour interval level of community presents a similar pattern with that of monthly level, the southern concentration of high value clusters expands to slightly to east, south and west.

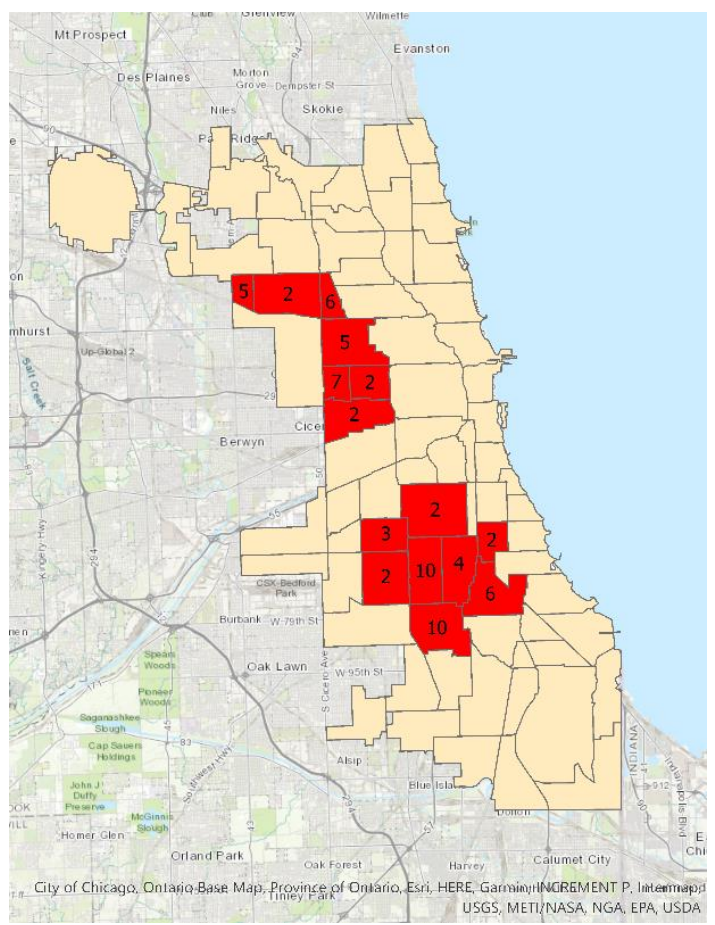

Figure 9 . High value clusters by month at community level 


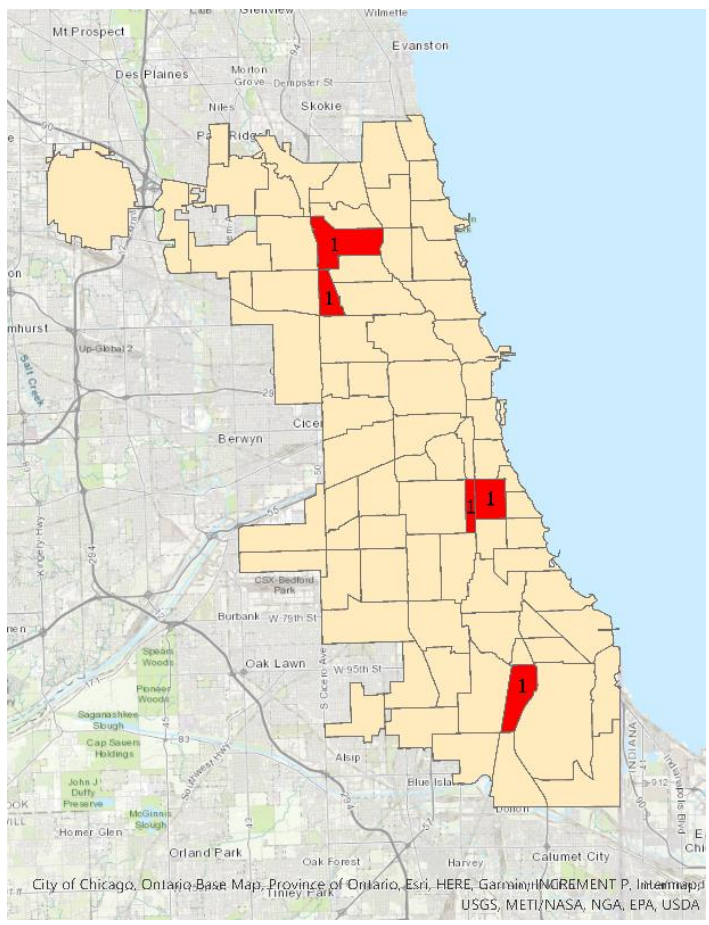

Figure 10. High value clusters by weekday at community level

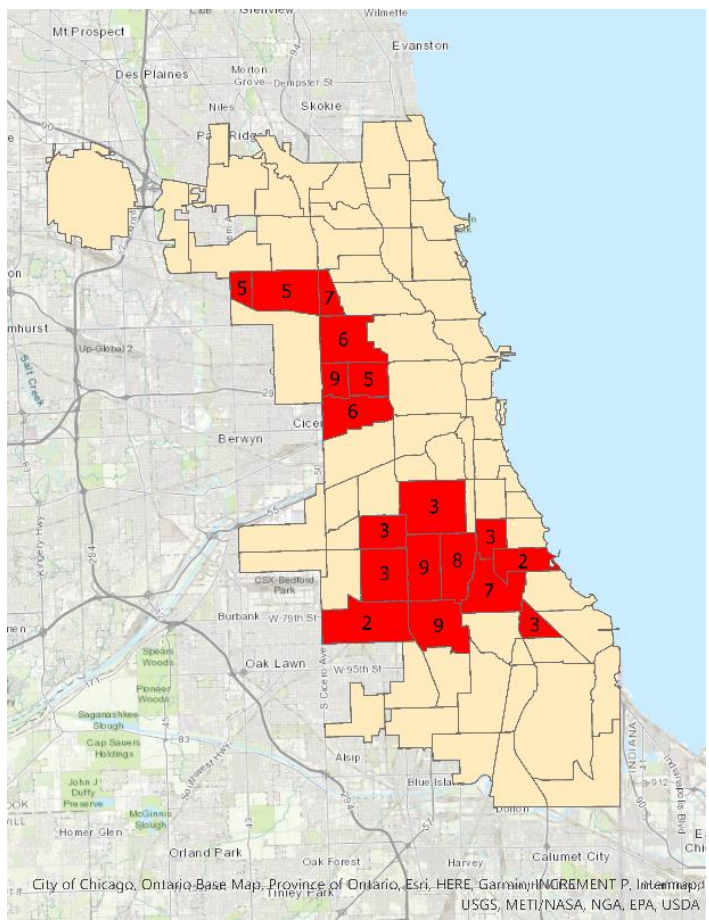

Figure 11. High value clusters by 2-hour interval in a day at community level

At the police beat's monthly level, one concentration of high value clusters is identified in the middle to south part of Chicago, with several sparsely high value clusters in the northeast and south (Figure 12). Similar patter can be found at the police beat's weekday level with less clusters though (Figure 13). At the twohour interval level, more clusters are concentrated in the middle to south part of Chicago (Figure 14).

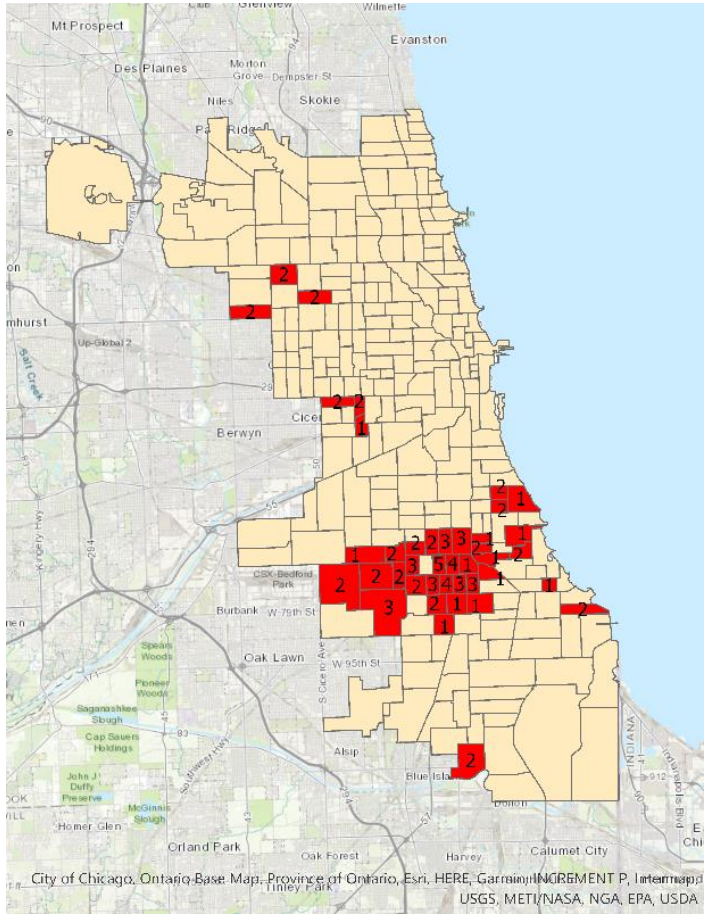

Figure 12. High value clusters by month at police beat level

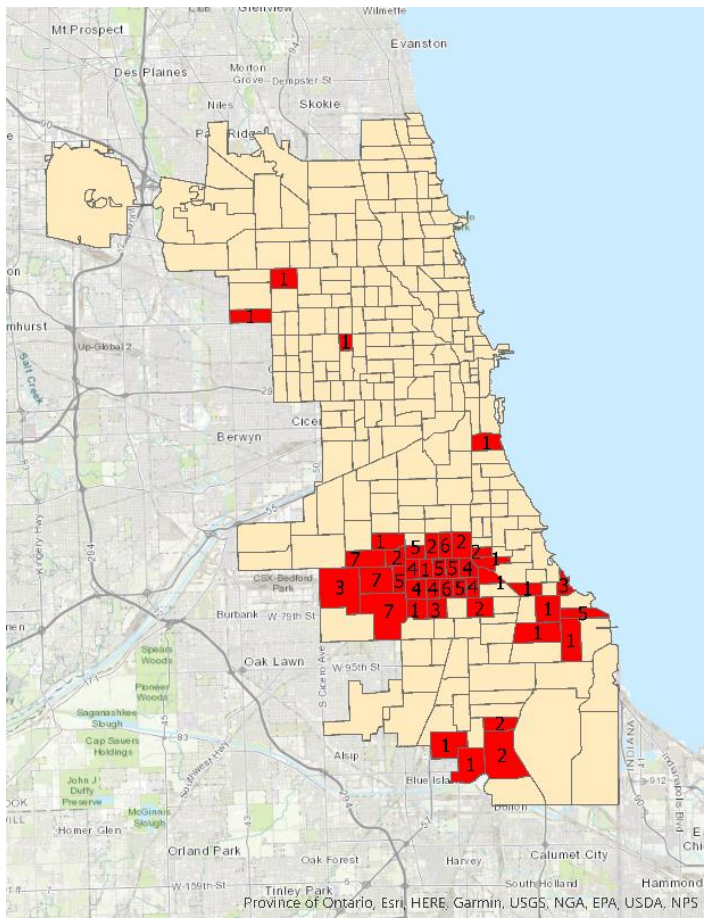

Figure 13. High value clusters by weekday at police beat level 


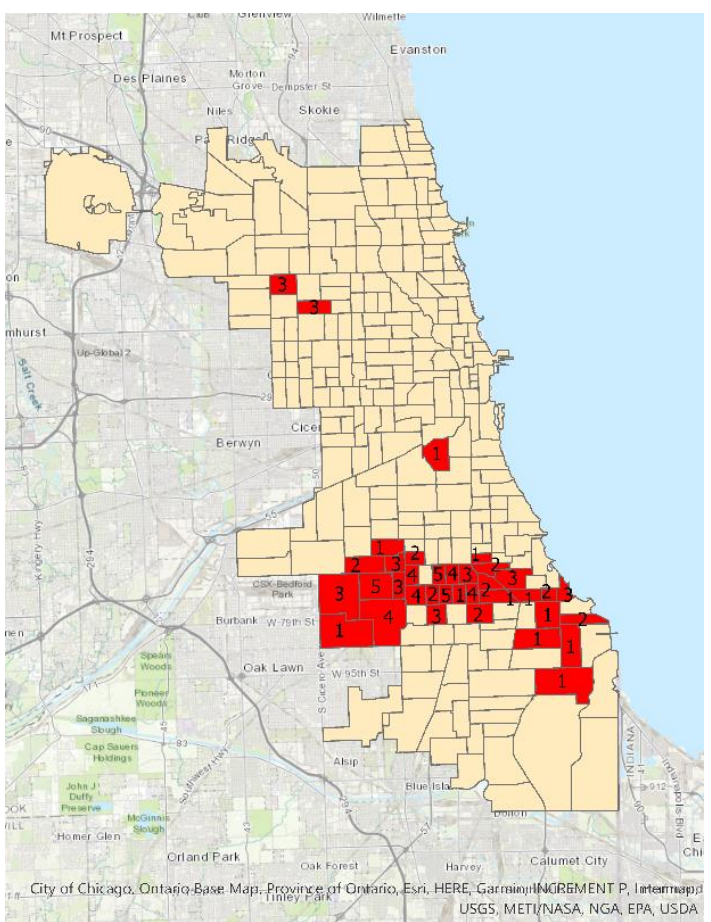

Figure 14. High value clusters by 2-hour interval in a day at police beat level

In general, the middle to south part of Chicago has the most spatiotemporal clusters of burglary crimes between 2006 and 2016, except for spatiotemporal scale of community and weekday. Targeting policing could be planned according to the analysis results that will lead to the more effective police resource allocation and crime prevention, such as increasing police patrols for a certain time slot during a certain weekday of a certain month.

\section{CONCLUSIONS}

This paper examines the multi-spatiotemporal patterns of burglary crimes in Chicago between 2006 and 2016. Three spatial scales: police district, community and police beat, are integrated with three temporal scales: one month interval in a year, one day interval in a week and 2-hour interval in a day. The burglary crime data set was aggregated into the six spatiotemporal scales and six types of spatiotemporal slice data are generated for analysis. A spatiotemporal weight matrix is generated for each of the spatiotemporal slice data, and the Getis-Ord $G_{i} *$ statistic is calibrated against the spatiotemporal slices to identify spatiotemporal clusters of burglary crimes in Chicago.

The spatiotemporal slice data with calculated $G_{i} *$ statistics can be used in a GIS environment to explore the spatiotemporal patterns of burglary crimes. For example, people can query that if a police beat exhibits a significant cluster of burglary on Wednesday over the time period of 2006 to 2016. It is found that generally the middle to south part of Chicago had the most burglary crime clusters at any spatiotemporal scales. However, the distribution of burglary clusters varies spatiotemporally. The frequency that a spatial unit (i.e. police district, community or police beat) is identified as a cluster regarding a time interval varies significantly. Authorities can utilize the information provided by the analysis to better plan policies on target policing and crime preventions. Future research should consider the relationships between burglary crimes and environments to explain the spatiotemporal process.

\section{REFERENCES}

Conrow, L., Aldstadt, J., \& Mendoza, N. S., 2015. A spatiotemporal analysis of on-premises alcohol outlets and violent crime events in Buffalo, NY. Applied Geography, 58 (0),pp. 198205 .

Getis, A., \& Ord, J. K., 1995. Local Spatial Autocorrelation Statistics: Distributional Issues and an Application. Geographical Analysis, 27 (4).

Getis, A., \& Ord., J. K., 1992. The Analysis of Spatial Association by Use of Distance Statistics. Geographical Analysis, 24 (3).

Hill, B., \& Paynich, R., 2014. Fundamentals of Crime Mapping. Jones \& Bartlett Learning, Burlington, MA, pp. 620.

Johnson, D., 2013. The space/time behaviour of dwelling burglars: Finding near repeat patterns in serial offender data. Applied Geography, 41 (0),pp. 139-146.

Ye, X., \& Liu, L., 2012. Spatial crime analysis and modeling. Annals of GIS, 18 (3),pp. 157-157.

Ye, X., \& Wu, L., 2011. Analyzing the dynamics of homicide patterns in Chicago: ESDA and spatial panel approaches. Applied Geography, 31 (2),pp. 800-807.

Ye, X., Xu, X., Lee, J., Zhu, X., \& Wu, L., 2015. Space-time interaction of residential burglaries in Wuhan, China. Applied Geography, 60,pp. 210-216.

Zhang, H., \& McCord, E. S., 2014. A spatial analysis of the impact of housing foreclosures on residential burglary. Applied Geography, 54,pp. 27-34. 